\title{
Do we overprescribe antibiotics?
}

\author{
Antibiotic prescribing by general dental practitioners in the Greater Glasgow Health Board, Scotland \\ by K. M. Royand J. Bagg Br Dent J2000; 188: 674-676
}

\section{Objective}

To investigate antibiotic prescribing patterns by general dental practitioners (GDPs) in the Greater Glasgow Health Board Area, Scotland.

\section{Study design}

A $10 \%$ sample of prescriptions were selected at random from 35,545 prescriptions written by GDPs over a 6-month period.

\section{Main outcome measures}

Absolute and relative frequencies were used to describe the different classes of antibiotics used and the variations in prescribing practice.

\section{Results}

GDPs prescribed a wide range of antibiotics. Seventeen different antibiotics were prescribed with amoxycillin, metronidazole and penicillin $\mathrm{V}$ accounting for almost $90 \%$ of the prescriptions. In general the antibiotics were prescribed at the British National Formulary (BNF) recommended doses. There were, however, wide variations in the frequencies and durations of the prescriptions for all antibiotics.

\section{Conclusions}

The present study provides evidence of sub-optimal prescribing of antibiotics by dentists in Scotland, with considerable variation from the recommended frequencies and doses.

\section{In brief}

- In order to retain the effectiveness of our current selection of antimicrobial agents, they must be used prudently.

- As part of the process of devising rational antibiotic policies it is essential to collect baseline data on what is currently prescribed by general dental practitioners.

- This study contributes to our current knowledge by demonstrating the wide variations in frequencies and durations of prescriptions for all antibiotics.

- This work will contribute to our understanding of those particular clinical issues where there is much confusion over which antibiotic to use (if any), how much to use and for how long.

\section{Comment}

There is a widespread belief among 1 dentists that antibiotic overprescribing is not associated with dentistry, it is a problem for medics. This timely report from the Infection Research Group in Glasgow goes some way to dispel this myth.

Dr Roy and her colleagues have shown that dentists in Glasgow do prescribe a lot of antibiotics. This overprescribing can only cause the selection and emergence of resistant bacterial strains. The Glasgow dentists also overprescribe antibiotics in incorrect doses, with inappropriate periodicity and duration.

The use of amoxicillin for periods greater than 5 days seems a little odd, but in this study it was prescribed for 20 days at $250 \mathrm{mg}$ and $500 \mathrm{mg}$. This reviewer can think of no indication for such long and inappropriate prescriptions by a general dental practitioner. In addition, the majority of the prescribers used amoxicillin four times rather than three times daily, this betrays an ignorance of the pharmacokinetics of this important antibiotic. Sadly this problem is not confined to Glasgow, similar results have been obtained in two shortly to be published English studies.

What is the answer to the problem of poor antibiotic prescribing? A number of things need urgent change and the first is that dental practitioners need clear advice on prescribing antibiotics. The rational use of antibiotics should start in the dental schools where clear and simple policies should be taught. Unfortunately this is not the case in all dental schools and antibiotic usage is often taught on an apprenticeship system in clinical areas rather than by use of clear scientifically based policies. The Dental Practitioner's Formulary is widely used by dentists and is designed as a 'guide book,' and is useful for all grades of the profession from consultant to newly qualified vocational trainee. The DPF cannot therefore be definitive for all the situations in general dental practice. The Royal College of General Dental Practitioners in England is to issue antimicrobial-prescribing standards soon and this may provide the clearly needed help to dental practitioners.

In the meantime next time you reach for the prescription pad think seriously whether you need an antibiotic. It really does matter.

\section{V. Martin}

Senior Lecturer and Honorary Consultant Microbiologist, University of Liverpool 